\title{
Erratum to: How students experience and navigate transitions in undergraduate medical education: an application of Bourdieu's theoretical model
}

\author{
Dorene F. Balmer • Boyd F. Richards • Lara Varpio
}

Published online: 13 February 2015

(C) Springer Science+Business Media Dordrecht 2015

\section{Erratum to: Adv in Health Sci Educ \\ DOI 10.1007/s10459-015-9588-y}

The following disclaimer should have been included in the article:

The views expressed herein are those of the authors and do not necessarily reflect those of the Department of Defense or other federal agencies.

The online version of the original article can be found under doi:10.1007/s10459-015-9588-y.

D. F. Balmer $(\square)$

Baylor College of Medicine/Texas Children's Hospital, 6621 Fannin Street, A188.03,

Houston, TX 77030, USA

e-mail: dorene.balmer@bcm.edu

B. F. Richards

Columbia University Medical Center, New York, NY, USA

L. Varpio

Uniformed Services University of the Health Sciences, Bethesda, MD, USA 